\title{
Effect of anesthesia level on murine cardiac function [version
}

\section{1; peer review: 1 approved, 1 approved with reservations]}

\author{
Fabien Picard ${ }^{1}$, Francois Depret ${ }^{1}$, Sergio Zanotti-Cavazzoni ${ }^{2}$, Steven Hollenberg ${ }^{1}$ \\ ${ }^{1}$ Division of Cardiovascular Diseases, Cooper University Hospital, Cooper Medical School of Rowan University, Camden, NJ, NJ 08103, \\ USA \\ 2Division of Critical Care Medicine, Cooper University Hospital, Cooper Medical School of Rowan University, Camden, NJ, 08103, USA
}

V1 First published: $22 \mathrm{Jul}$ 2014, 3:165

https://doi.org/10.12688/f1000research.3873.1

Latest published: 22 Jul 2014, 3:165

https://doi.org/10.12688/f1000research.3873.1

\section{Abstract}

Background: Echocardiography allows for sensitive and non-invasive assessment of cardiac function in mice, but requires sedation and immobility, which influences cardiac performance. Minimizing the hemodynamic effects of anesthesia is extremely important for improving the applicability of animal models to the clinical setting. We sought to evaluate the effects of isoflurane dose on myocardial function in a murine model.

Methods: Twelve healthy C57BL/6 mice were studied with three different isoflurane anesthesia regimens: deep anesthesia with an objective of heart rate (HR) between 350 and 400 beats per minute (bpm), light anesthesia with an objective of HR between 475 and 525 bpm and just before the mice woke up (>575 bpm). Using a highresolution ultrasound system, stroke volume, cardiac output, left ventricle dimension and fractional shortening were recorded.

Results: Fractional shortening was not statistically different in the awake group and the light anesthesia group (49 $\pm 5 \%$ in awake mice vs. $48 \pm 5 \% ; p=0.62)$, whereas it was different compared to the deep anesthesia group $(31 \pm 5 \%, \mathrm{p}<0.0001$ compared to both groups). Similar results were found for stroke volume $(41.4 \pm 5.8 \mathrm{ml}$ vs. $41.6 \pm 6.9 \mathrm{ml}$; $\mathrm{p}=0.81$ and $35 \pm 8.3 \mathrm{ml} ; \mathrm{p}<0.05$ compared to both groups). Cardiac output was slightly lower in the light anesthesia group compared to the awake group $(21.9 \pm 3.6 \mathrm{ml} / \mathrm{min}$ vs. $25.6 \pm 3.3 ; \mathrm{p}=0.02)$ due to HR significant difference ( $522 \pm 17$ bpm vs. $608 \pm 23$ bpm; $p<0.0001)$. Conclusions: Doppler echocardiography can be performed under very light anesthesia using small doses of isoflurane without influencing cardiac inotropic function. This technique allows for accurate and reproducible assessment of cardiac function while minimizing hemodynamic perturbations.

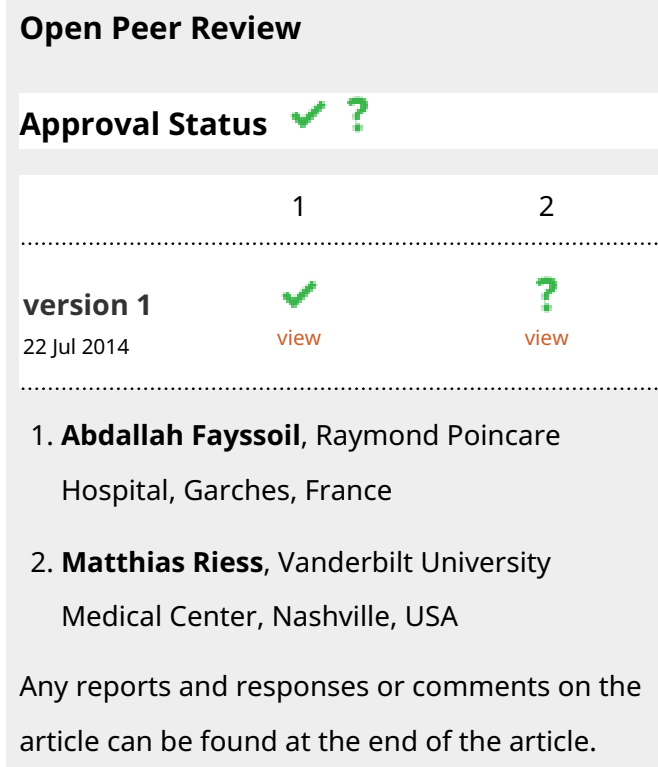


Corresponding authors: Fabien Picard (fabien.picard@live.fr), Francois Depret (depret.francois@gmail.com)

Competing interests: No competing interests were disclosed.

Grant information: F.D. was supported by a grant from Assistance Publique - Hôpitaux de Paris (Année Recherche).

Copyright: $\odot 2014$ Picard F et al. This is an open access article distributed under the terms of the Creative Commons Attribution License, which permits unrestricted use, distribution, and reproduction in any medium, provided the original work is properly cited. Data associated with the article are available under the terms of the Creative Commons Zero "No rights reserved" data waiver (CC0 1.0 Public domain dedication).

How to cite this article: Picard F, Depret F, Zanotti-Cavazzoni $S$ and Hollenberg S. Effect of anesthesia level on murine cardiac function [version 1; peer review: 1 approved, 1 approved with reservations] F1000Research 2014, 3:165

https://doi.org/10.12688/f1000research.3873.1

First published: 22 Jul 2014, 3:165 https://doi.org/10.12688/f1000research.3873.1 


\section{Introduction}

Animal models of disease can provide important insights into pathophysiological mechanisms and allow for evaluation of novel therapies. Murine models have been widely used for these purposes: cardiac and vascular morphologic differences between mice, rats, and humans are fairly subtle, and many physiological characteristics are comparable ${ }^{1}$.

For hemodynamic assessments in murine models, it is critical to develop approaches for accurate and reproducible measurements of cardiac morphology and function in intact animals. The parameters measured in mice are close to those predicted by allometric formulas when compared to other mammals, supporting the view that physiological mechanisms in mice are closely related to those in humans. Echocardiography (echo) is convenient, quick, and safe and allows for consecutive and repeated evaluations of cardiovascular physiologic and pathologic characteristics in live animals. Echo has been widely applied in determining cardiac phenotypes and functions in murine models ${ }^{2-7}$. Anesthesia is necessary to achieve the best technical results but has a potential downside in that it may induce myocardial depression. Minimizing the hemodynamic effects of anesthesia is extremely important for improving the applicability of animal models to the clinical setting, especially in models of shock in which hemodynamic perturbations are paramount.

One of the classical models of septic shock in mice is the cecal ligation and puncture model ${ }^{8}$; the anesthetic usually used in this model is ketamine. Ketamine is well known to produce profound bradycardia with effects on loading conditions and ventricular function, and to be more difficult to control once injected ${ }^{9}$. Compared to ketamine, inhalation anesthesia with isoflurane has currently been considered ideal for experimental studies in the mouse because of its rapid induction, easy control of the depth of anesthesia, and relatively stable heart rates (HR) and blood pressure during observations. It also seems to have the least myocardial depression compared to other anesthesia regimens ${ }^{10-13}$. Few data concerning echocardiographic evaluation of left ventricle (LV) function in anesthetized and non-anesthetized mice are available ${ }^{7}$. It is also known that deeper levels of anesthesia lower heart rate and produce more myocardial depression ${ }^{14}$. In fact heart rate can be used as a proxy for depth of anesthesia.

Some investigators have trained mice in order to perform echocardiography on awake mice, thus avoiding the potentially confounding effects of anesthesia ${ }^{7}$. The mice, however, need to be restrained, and these experiments induce adrenergic stress that may produce hemodynamic perturbations in their own right.

The optimal depth of anesthesia for reliable and relevant measurements by high-resolution echocardiography is not well studied. The aim of this study was to evaluate the effects of isoflurane dose on myocardial function in a murine model and to compare very low doses of isoflurane to a state in which the mice were off anesthesia. To evaluate whether a very light anesthesia using a small dose of isoflurane affected systolic cardiac function, we recorded cardiac performance in mice by using a high-resolution ultrasound system in three groups with different anesthesia regimens. The three groups were based on the depth of anesthesia corresponding to HR measurement: a deep anesthesia group corresponding to a low HR (350-400 bpm), light anesthesia corresponding to a high HR (475-525 bpm) and an awake group in which cardiac performance was assessed just before the animals woke up (HR $>575 \mathrm{bpm})$. Left ventricle (LV) dimensions, systolic function and aortic pulsed wave (PW) Doppler were recorded.

\section{Materials and methods} Animals

A total of 12 healthy male C57BL/6J mice (10-12 weeks old, Jackson Laboratories, Bar Harbor, ME) weighing 26 to $30 \mathrm{~g}$ were included in this study. They were housed in the Central Animal Facility of the University of Medicine and Dentistry of New Jersey (UMDNJ), Camden, NJ, USA, at $20^{\circ} \mathrm{C}$ at $60 \%$ humidity with a 12:12-hr light-dark cycle and fed on a standard diet and water ad libitum, for at least seven days before experiments, to avoid preconditioning. Animal experiments were performed in accordance with the guidelines of the National Institutes of Health Guide for the Care and Use of Laboratory Animals (revised 1996; National Institutes of Health, Bethesda, MD), and the Animal Care and Use Committee of UMDNJ approved the study protocol. Animals were returned to the vivarium for other experiments after the study.

\section{Experimental protocols}

To assess the effect of different anesthesia regimens on cardiac function using isoflurane, we performed 36 echocardiographic studies on 12 mice and used HR as a proxy for the depth of anesthesia.

We first performed echocardiography on 12 mice with a deep anesthesia regimen corresponding to a low HR (350-400 bpm), and did a second echocardiographic study on the same mice three days later under light anesthesia titrated to a higher HR (475-525 bpm). The anesthesia was then discontinued and the same parameters were recorded continuously until the animals woke up, when they generally moved and the images were lost. The images taken just prior to movement were used for the awake group. The HRs in the awake group were regularly higher than $\mathrm{HR}>575 \mathrm{bpm}$. The ranges of high and low HRs were determined according to previous reports on the relationship between the HR and cardiac function ${ }^{15}$.

\section{Anesthesia and echocardiography preparation}

Isoflurane induction was performed in an induction box with $3 \%$ isoflurane (Baxter) in pure medical oxygen. After the righting reflex disappeared, the animal was fixed in supine position on a heating pad (Vevo ${ }^{\circledR}$ Integrated Rail System, Visualsonics, Inc) to maintain normothermia and electrocardiographic limb electrodes were placed. The mouse was allowed to breathe spontaneously, and the chest was shaved to minimize ultrasound attenuation. Acoustic coupling gel (Aquasonic ${ }^{\circledR}$ 100, Parker Laboratories, Inc) was applied to the thorax surface to optimize the visibility of the cardiac chambers and wall movements. Anesthesia was maintained with $2 \%$ isoflurane for the low HR group and with $0.5 \%$ isoflurane for the high HR group. If the HR was found to be above the required range, the isoflurane concentration could be temporarily increased to $4 \%$ and then decreased to $2 \%$ after the HR reached the required level. Contrarily, if the HR was below the required range, the isoflurane concentration could be set at $0.25 \%$ and then increased. 


\section{Echocardiographic measurements}

A Vevo ${ }^{\circledR} 770$ high-resolution ultrasound system (VisualSonics, Inc) equipped with a $30-\mathrm{MHz}, 100$-frame-per-second micro-visualization scan head was used to perform echocardiography. The echocardiographic measurements were recorded according to standard methods from previously published reports ${ }^{7,11,16,17}$. A parasternal long-axis B-mode image was acquired with appropriate positioning of the scan head so that the maximum LV length could be identified, then a clockwise $90^{\circ}$ rotation at the papillary muscle level was performed to obtain the parasternal short-axis view. The M-mode cursor was positioned perpendicular to the anterior and posterior walls of the LV. From this view, wall thickness and chamber dimensions were measured. Image loops were captured and included at least ten cardiac cycles. Data were averaged from at least two cycles per loop. End-diastole or end-systole was defined as the maximal or minimal LV diastolic or systolic diameter, respectively. The parameters obtained from M-mode tracings included the LV anterior wall end-diastolic thickness (LVAWTd), LV anterior wall end-systolic thickness (LVAWTs), LV posterior wall end-diastolic thickness (LVPWTd), LV posterior wall end-systolic thickness (LVPWTs), LV end-diastolic diameter (LVEDD) and LV end-systolic diameter (LVESD). Other parameters such as the LV end-diastolic volume (LVEDV), LV end-systolic volume (LVESV), ejection fraction (EF), fractional shortening (FS) were calculated using the following formulas (VisualSonics Vevo ${ }^{\circledR} 770$ Imaging System, Operator Manual):

(1) $\operatorname{LVEDV}=[7.0 \div(2.4+\mathrm{LVEDD})] \times$ LVEDD 3 ;

(2) $\operatorname{LVESV}=[7.0 \div(2.4+\operatorname{LVESD})] \times \operatorname{LVESD} 3$;

(3) $\% \mathrm{EF}=100 \times[(\mathrm{LVEDV}-\mathrm{LVESV}) \div \mathrm{LVEDV}]$;

(4) $\% \mathrm{FS}=100 \times[(\mathrm{LVEDD}-\mathrm{LVESD}) \div \mathrm{LVEDD}]$;

Aortic flow velocity time integral (AV VTI) images were measured with PW Doppler imaging in the suprasternal orientation. The Doppler angle was modulated slightly to allow the interrogation beam almost parallel to aortic flow so that the maximum flow velocity was obtained. PW Doppler signals from at least three cardiac cycles were averaged. Stroke volume (SV) and cardiac output (CO) were calculated using the following formulas (VisualSonics Vevo ${ }^{\circledR} 770$ Imaging System, Operator Manual):

(5) $\mathrm{SV}=\left[(\text { aortic root diameter })^{2} \times\right.$ velocity-time integral $\left.\times \pi / 4\right]$;

(6) $\mathrm{CO}=\mathrm{SV} \times \mathrm{HR}$;

Intra-observer and inter-observer variability

To determine the intra-observer variability of echocardiographic measurements, one observer repeated the echocardiographic data analysis for eight randomly chosen mice on different days. Two observers measuring the already recorded image estimated interobserver variability. Intra-observer and inter-observer errors were calculated as the difference between the two observations divided by the mean and expressed as a percentage. Intra- and inter-class correlation coefficients (ICC) were used to evaluate the agreement for both intra- and inter-observer variability. The ICC value is the ratio of the between-subject variance to the sum of the between-subject variance and the within-subject variance. The ICC values can be considered as poor (less than 0.40), fair (0.40-0.59), good (0.60$0.74)$, and excellent $(0.75-1.00)^{18}$.

\section{Statistical analysis}

Data were averaged and reported as mean \pm SD unless otherwise stated. Statistical analysis was performed using SPSS software (Version 19, SPSS, Chicago). Whenever appropriate, the data for the awake and the anesthetized animals were compared with Student's $t$-test for matched pairs. Two-sided $\mathrm{p}$-values $<0.05$ were considered as significant. Paired $t$-tests were used for intra-observer and inter-observer comparisons. Variation was evaluated by determination of ICC. This measure indicates excellent agreement if $>0.75$, fair to good if between 0.4 and 0.75 , and poor if $<0.4$.

\section{Results}

Echocardiography in non-anesthetized versus anesthetized mice

There were no differences in the baseline HR among the mice we tested.

Deep anesthesia group versus light and awake groups In the deep anesthesia group, HR was significantly lower than in the light and awake group ( $363 \pm 27 \mathrm{bpm}$ vs. $522 \pm 17$ and $608 \pm 23 \mathrm{bpm}$; $\mathrm{p}<0.0001$, Table 1, Figure 1). In addition, there was a significant reduction in FS between the deep anesthesia group and both the light and the awake group $(31 \pm 5 \%$ vs. $48 \pm 5$ and $49 \pm 5 \%$; $\mathrm{p}<0.0001)$. EF was also lower in the deep anesthesia group, as compared to the light and to the awake group $(59 \pm 7 \%$ in the deep anesthesia group and $80 \pm 5 \%$ and $81 \pm 5 \%$ in the light group and the awake group respectively; $\mathrm{p}<0.0001)$, as AV VTI $(2.74+/$ $0.59 \mathrm{~cm}$ in the deep anesthesia group and $3.31 \pm 0.45 \mathrm{~cm}$ in the awake group; $\mathrm{p}=0.048), \mathrm{SV}(35.01 \pm 8.27 \mu \mathrm{l}$ in the deep anesthesia group and $41.35 \pm 5.79 \mu \mathrm{l}$ in the awake group; $\mathrm{p}=0.048$ ) and $\mathrm{CO}(12.67 \pm 3.08 \mathrm{ml} / \mathrm{min}$. in the deep anesthesia group and $25.61 \pm 3.31 \mathrm{ml} / \mathrm{min}$. in the awake group; $\mathrm{p}<0.0001$ ) (Table 1 , Figure 1).

LVEDD was slightly higher on the deep anesthesia group $(3.74 \pm 0.39 \mathrm{~mm})$ but no statistically significant difference could be found between the light anesthesia group $(3.0 \pm 0.33 \mathrm{~mm} ; \mathrm{p}=0.0827)$ and the awake group $(3.37 \pm 0.41, \mathrm{p}=0.0864)$ (Table 1$)$.

Light anesthesia group versus awake group

HR was significantly lower in the light anesthesia group compared to the awake group ( $522 \pm 17$ bpm vs. $608 \pm 23$ beats/min; $\mathrm{p}<0.0001)$ (Table 1, Figure 1). Concerning the FS values, there were no statistical differences between the light anesthesia group and the awake group ( $48 \pm 5 \%$ vs. $49 \pm 5 \%$; $\mathrm{p}=0.6212)$. The same results were found for $\mathrm{EF}(80 \pm 5 \%$ in the light anesthesia group; $\mathrm{p}=0.5536$ when compared to the awake group), AV VTI $(3.26+/-0.5 \mathrm{~cm}$ in the light anesthesia group; $\mathrm{p}=0.8$ when compared to the awake group) and $\mathrm{SV}$ $(41.61+/-6.86 \mu \mathrm{l}$ in the light anesthesia group; $\mathrm{p}=0.81$ when compared to the awake group).

Although SV was similar in both groups, $\mathrm{CO}$ was significantly lower in the light anesthesia group, $(21.90+/-3.56 \mathrm{ml} / \mathrm{min}$. in the 
Table 1. Comparisons of echocardiographic measurements between deep anesthesia, light anesthesia and awake echocardiography.

\begin{tabular}{|l|l|l|l|}
\hline Parameters & Deep anesthesia $(\mathbf{n}=12)$ & Light anesthesia $(\mathbf{n}=12)$ & Awake $(\mathbf{n}=12)$ \\
\hline HR $(\mathrm{bpm})$ & $362.92+/-27.26^{\ddagger \star}$ & $522.5+/-16.72^{\# \star}$ & $608.33+/-22.8^{\# \ddagger}$ \\
\hline LVAWTd $(\mathrm{mm})$ & $0.86+/-0.08^{\star}$ & $0.96+/-0.14$ & $1.00+/-0.14^{\#}$ \\
\hline LVEDD $(\mathrm{mm})$ & $3.74+/-0.39$ & $3.40+/-0.33$ & $3.37+/-0.41$ \\
\hline LVPWTd $(\mathrm{mm})$ & $0.83+/-0.23$ & $0.94+/-0.21$ & $0.96+/-0.23$ \\
\hline LVAWTs $(\mathrm{mm})$ & $1.21+/-0.18^{\ddagger \star}$ & $1.47+/-0.26^{\#}$ & $1.56+/-0.28^{\#}$ \\
\hline LVESD $(\mathrm{mm})$ & $2.59+/-0.39^{\ddagger \star}$ & $1.76+/-0.27^{\#}$ & $1.73+/-0.32^{\#}$ \\
\hline LVPWTs $(\mathrm{mm})$ & $1.23+/-0.23^{\ddagger \star}$ & $1.54+/-0.19^{\#}$ & $1.53+/-0.21$ \\
\hline AV VTI $(\mathrm{cm})$ & $2.74+/-0.59^{\ddagger \star}$ & $3.26+/-0.5^{\#}$ & $3.31+/-0.45^{\#}$ \\
\hline LVEDV $(\mu \mathrm{l})$ & $60.66+/-14.8$ & $48.13+/-11.19$ & $47.45+/-13.91$ \\
\hline LVESV $(\mu \mathrm{l})$ & $25.33+/-9.37^{\ddagger \star}$ & $9.58+/-3.69^{\#}$ & $9.34+/-4.39^{\#}$ \\
\hline EF $(\%)$ & $59.09+/-7.51^{\ddagger \star}$ & $80.30+/-4.97^{\#}$ & $80.95 \%+/-4.83^{\#}$ \\
\hline FS $(\%)$ & $30.93+/-4.92^{\ddagger \star}$ & $48.26+/-5.57^{\#}$ & $48.84+/-4.84^{\#}$ \\
\hline SV $(\mu l)$ & $35.01+/-8.27^{\ddagger \star}$ & $41.61+/-6.86^{\#}$ & $41.35+/-5.79^{\#}$ \\
\hline CO $(\mathrm{ml} / \mathrm{min})$ & $12.67+/-3.08^{\ddagger \star}$ & $21.90+/-3.56^{\# \star}$ & $25.61+/-3.31^{\# \neq}$ \\
\hline
\end{tabular}

$\mathrm{HR}=$ Heart rate; LVAWTd/s=Left ventricle anterior wall end-diastolic/systolic thickness; LVEDD= Left ventricle end-diastolic diameter; LVPWTd/s= Left ventricle posterior wall end-diastolic/systolic thickness; LVESD= Left ventricle end-systolic diameter; LVEDV= Left ventricle end-diastolic volume; LVESV= Left ventricle end-systolic volume; $E F=$ ejection fraction; $F S=$ fractional shortening; $C O=$ cardiac output;. Values are means +/- SD. N = 12 animals for the three different anesthetic regimens. \#p $<0.05$ compared to deep anesthesia. ${ }^{\ddagger} p<0.05$ compared to light anesthesia. ${ }^{\star} p<0.05$ compared to awake mice.
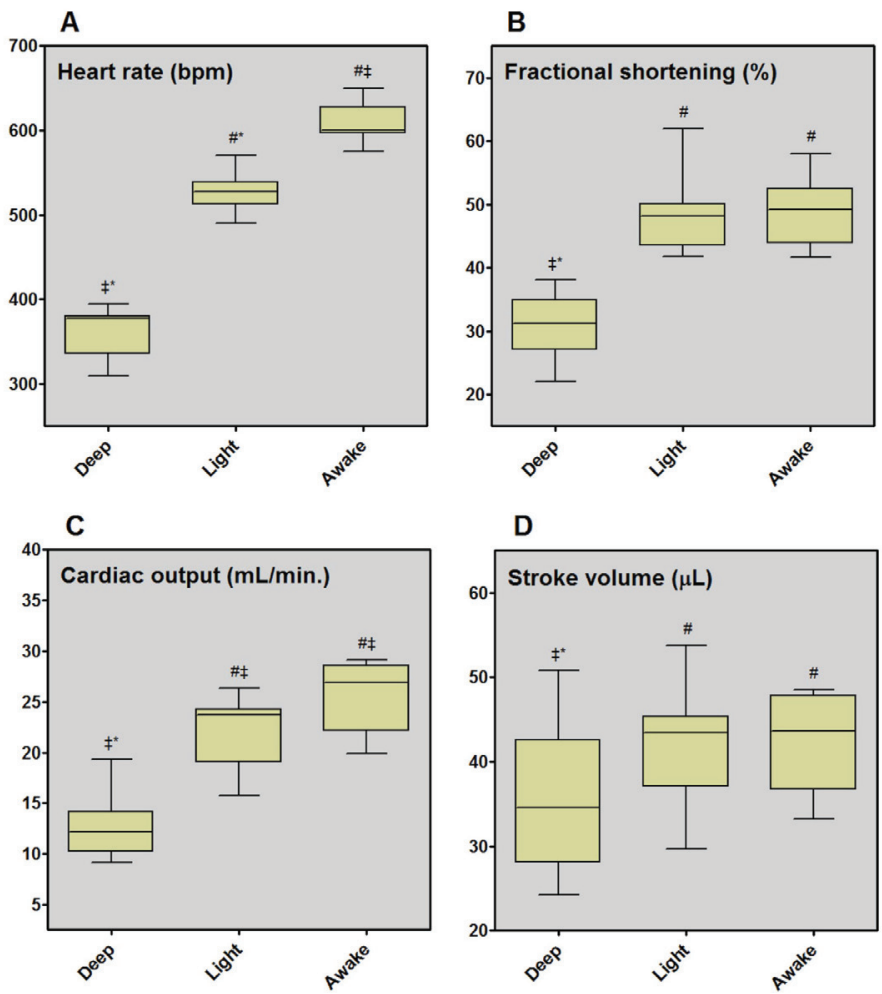

Figure 1. Impact of the three different anesthetic regimens on cardiac performance. Cardiac performance in animals anesthetized with isoflurane in a deep anesthesia, a light anesthesia or just before waking. Heart rate (A), fractional shortening (B), cardiac output (C), stroke volume (D) were studied.

$\mathrm{N}=12$ animals for the three different anesthetic regimens

$\# p<0.05$ compared to deep anesthesia. ${ }^{\ddagger} p<0.05$ compared to light anesthesia.

${ }^{*} \mathrm{p}<0.05$ compared to awake mice. 
light anesthesia group; $\mathrm{p}=0.02$ when compared to the awake group) probably due to the significant difference in HR (Table 1, Figure 1).

\section{Variability and reproducibility}

The reproducibility of echocardiographic measurements [LVAWTd $(\mathrm{mm})$, LVESD $(\mathrm{mm})$, LVPWTd $(\mathrm{mm})$, LVAWTs $(\mathrm{mm})$, LVEDD (mm), LVPWTs (mm), FS (\%), Peak AV ( $\mathrm{mm} / \mathrm{s})$, AV VTI $(\mathrm{cm})]$ in our study was good to excellent (Table 2) for both intra-observer variability (correlation coefficient: 0.95-0.99) and inter-observer variability (correlation coefficient: $0.67-0.99$ ).

Inter and intra-observer reproducibility data for effect of anesthesia on murine cardiac function

\section{Data Files}

http://dx.doi.org/10.6084/m9.figshare.1102780

\section{Discussion}

Our study shows that there was no significant difference in cardiac inotropic performance evaluated by echocardiography between mice under very light isoflurane anesthesia (HR 475-550 bpm) and awake mice (HR>575 bpm), but that myocardial depression occurred if the anesthesia was too deep ( $<400 \mathrm{bpm})$. Echocardiographic evaluation of cardiac function in mice is carried out, most of the times, with the animals under anesthesia, which may alter cardiac function and thereby confound interpretation of the data. Thus, to assess cardiac morphology and function in small animals, it is critical to develop the best technique for accurate and repeated measurements.

Table 2. Echocardiographic variability of M-Mode and PW Doppler data.

\begin{tabular}{|l|l|l|l|l|}
\hline Parameter & $\begin{array}{l}\text { Intra-observer } \\
\text { Error (\%) }\end{array}$ & ICC & $\begin{array}{l}\text { Inter-observer } \\
\text { Error (\%) }\end{array}$ & ICC \\
\hline LVAWTd $(\mathrm{mm})$ & $-\mathbf{0 . 8} \pm \mathbf{1 . 4}$ & $\mathbf{0 . 9 6}$ & $\mathbf{2 . 7} \pm \mathbf{2 . 3}$ & $\mathbf{0 . 8 6}$ \\
\hline LVESD $(\mathrm{mm})$ & $\mathbf{1 . 1} \pm \mathbf{0 . 8}$ & $\mathbf{0 . 9 8}$ & $\mathbf{2 . 9} \pm \mathbf{1 . 6}$ & $\mathbf{0 . 9}$ \\
\hline LVPWTd (mm) & $-\mathbf{1 . 4} \pm \mathbf{2 . 4}$ & $\mathbf{0 . 9 8}$ & $\mathbf{7 . 0} \pm \mathbf{4 . 2}$ & $\mathbf{0 . 8 9}$ \\
\hline LVAWTs $(\mathrm{mm})$ & $\mathbf{1 . 5} \pm \mathbf{1 . 3}$ & $\mathbf{0 . 9 5}$ & $\mathbf{9 . 5} \pm \mathbf{2 . 8}$ & $\mathbf{0 . 6 7}$ \\
\hline LVEDD $(\mathrm{mm})$ & $\mathbf{1 . 0} \pm \mathbf{2 . 2}$ & $\mathbf{0 . 9 8}$ & $\mathbf{0 . 7} \pm \mathbf{3 . 0}$ & $\mathbf{0 . 9 5}$ \\
\hline LVPWTs $(\mathrm{mm})$ & $-\mathbf{0 . 9} \pm \mathbf{1 . 4}$ & $\mathbf{0 . 9 8}$ & $\mathbf{3 . 8} \pm \mathbf{2 . 6}$ & $\mathbf{0 . 8 6}$ \\
\hline FS $(\%)$ & $\mathbf{0 . 2} \pm \mathbf{8}$ & $\mathbf{0 . 9 6}$ & $\mathbf{2 . 2} \pm \mathbf{3 . 0}$ & $\mathbf{0 . 8 9}$ \\
\hline AV VTI $(\mathrm{cm})$ & $-\mathbf{1 . 3} \pm 1.8$ & $\mathbf{0 . 9 9}$ & $-\mathbf{0 . 5} \pm \mathbf{2 . 7}$ & $\mathbf{0 . 9 8}$ \\
\hline
\end{tabular}

LVEDD = Left ventricle end-diastolic diameter; LVESD= Left ventricle endsystolic diameter; LVAWTd/s=Left ventricle anterior wall end-diastolic/systolic thickness; LVPWTd/s= Left ventricle posterior wall end-diastolic/systolic thickness; $\mathrm{FS}=$ fractional shortening; $\mathrm{AV} \mathrm{VTI}=$ Aortic valve velocity time integral.

Values are means +/-SEM; ICC, intra- and interobserver class correlation coefficients.

The ICC value is the ratio of the between-subject variance to the sum of the between-subject variance and the within-subject variance. The ICC values can be considered as poor (less than 0.40), fair (0.40-0.59), good (0.60-0.74), and excellent (0.75-1.00).
Performing echocardiography under very light anesthesia presents several advantages compared to using awake mice. First, anesthesia permits technically excellent echocardiography by avoiding movement from the mice. Second, as the mouse is under light anesthesia, measurements are not affected by stress, which can alter HR values.

Although HR has been suggested to affect echocardiographic measurements ${ }^{2,9,14,19}$, to our knowledge, no studies have compared the response of echocardiographic measurements between very light anesthesia and awake mice. Roth et al. ${ }^{14}$ assessed the reproducibility of echocardiographic parameters at several time points 12 days after isoflurane anesthesia, and they found that isoflurane anesthesia provided very good reproducibility on HR, FS and end-diastolic dimensions, compared to intraperitoneal tribromoethanol, ketamine/midazolam or ketamine-xylazine.

Non-invasive assessment of cardiac performance using echocardiography allows for serial evaluations of both function and morphologic parameters. Whether these studies should be performed in conscious restrained animals or under anesthesia remains uncertain. Studies in conscious restrained animals, even after training sessions to prevent bradycardia and make the animals familiar with the procedure, have often reported cardiac function parameters that are significantly higher (HR between 600 and $700 \mathrm{bpm}$ and FS\% between 55 to 65$)^{7,19-21}$ than those quoted for unrestrained animals with telemetry $(\mathrm{HR}=500-600 \mathrm{bpm}, \mathrm{FS} \%=35-50)^{21-24}$, suggesting sympathetic activation. This was also supported by the fact that responses to parasympathetic blockade with atropine or to administration of isoproterenol were not observed ${ }^{7}$. Moreover these values were normalized and a full response to isoproterenol was restored when midazolam, a benzodiazepine with little cardiodepressant effect, was administered ${ }^{25}$. A similar increase in sympathetic discharge was observed in animals with implanted telemeters when subjected to restraint ${ }^{26}$. In addition, despite animal training and manual restraint, adequate Doppler measurement may be difficult to obtain ${ }^{5}$. These data suggest that the response to restraint may induce such sympathetic activation that echocardiography functions as a stress test rather than providing an assessment of baseline status. As a matter of fact some of the reported values were comparable to those obtained during sub-maximal exercise $(\mathrm{HR}>650 \mathrm{bpm})^{21}$.

On the other hand, previous echocardiographic studies in anesthetized normal mice using various regimens of inhalation and injectable anesthetics at different doses have reported a wide range of LV dimensions (LVEDd 3.1-4.1 mm, FS\% 33-58\%, HR 250-600, SV $20-50 \mu \mathrm{l}$ and $\mathrm{CO} 8-30 \mathrm{ml} / \mathrm{min})^{20,25,27}$. Some of these have reported heart rates corresponding to $30-40 \mathrm{bpm}$ in humans when echocardiography was performed under anesthesia, suggesting profound hemodynamic depression ${ }^{28}$. On the basis of our data, we believe that we should use carefully titrated inhalational isofluorane anesthesia in order to minimize both the hemodynamic effect of deep anesthesia and the hemodynamic effect of sympathetic activation in awake mice. The anesthetic regimen is extremely important for improving applicability of animal models to clinical settings, especially in models of shock, in which hemodynamic perturbations are paramount. 
Our study did have some limitations. First, the timing of echocardiographic measurements after anesthesia was not studied. Nevertheless, Wu et al. ${ }^{29}$ recently found that when echocardiographic measurements were performed in mice with a HR between 475 and $525 \mathrm{bpm}$ ) after anesthesia, similar echocardiographic parameters could be obtained either a short or long time after anesthesia. As such, timing of the studies should not greatly affect the results. Second, echocardiography was performed on healthy mice and not on mice with pathological conditions. One might imagine, however, that hemodynamics in mice with cardiac disease or shock would be affected even more by anesthesia than healthy mice. Therefore, particular attention should be paid to the anesthesia regimen in mice under pathological conditions using carefully titrated inhalational anesthesia with isoflurane.

\section{Conclusion}

In conclusion, minimizing the hemodynamic effects of anesthesia is extremely important for improving the applicability of animal models to the clinical setting, especially in models of shock, in which hemodynamic perturbations are significant. We have shown that carefully titrated inhalational anesthesia with isoflurane allowed for echocardiography with minimal perturbation of hemodynamics. This anesthesia regimen allows for application in the study of cardiac function in murine models.
Data availability

figshare: Inter and intra-observer reproducibility data for effect of anesthesia on murine cardiac function, doi: http://dx.doi.org/10.6084/ m9.figshare. $1102780^{30}$

\section{Author contributions}

Fabien A. Picard performed data acquisition and analysis, interpreted the data and drafted the manuscript.

François L. Depret performed data acquisition and analysis, interpreted the data and drafted the manuscript.

Sergio Zanotti-Cavazzoni, performed the analysis, interpreted the data and contributed to drafting the manuscript.

Steven M Hollenberg performed the analysis, interpreted the data and contributed to drafting the manuscript.

\section{Competing interests}

No competing interests were disclosed.

\section{Grant information}

F.D. was supported by a grant from Assistance Publique - Hôpitaux de Paris (Année Recherche).
1. Fox J, Barthold S, Davison M, et al.: The mouse in Biomedical Research. Volume $1-4$, Second Edition (American College of Laboratory Animal Medicine). Burlington, MA: Elsevier; 2007

Reference Source

2. Kawahara Y, Tanonaka K, Daicho T, et al:: Preferable anesthetic conditions for echocardiographic determination of murine cardiac function. J Pharmacol Sci. 2005; 99(1): 95-104.

PubMed Abstract | Publisher Full Text

3. Plante E, Lachance D, Roussel E, et al:: Impact of anesthesia on echocardiographic evaluation of systolic and diastolic function in rats. J Am Soc Echocardiogr. 2006; 19(12): 1520-1525.

PubMed Abstract | Publisher Full Text

4. Pollick C, Hale SL, Kloner RA: Echocardiographic and cardiac Doppler assessment of mice. J Am Soc Echocardiogr. 1995; 8(5 Pt 1): 602-610. PubMed Abstract | Publisher Full Text

5. Rottman JN, Ni G, Brown M: Echocardiographic evaluation of ventricular function in mice. Echocardiography. 2007; 24(1): 83-89. PubMed Abstract | Publisher Full Text

6. Tanaka N, Dalton N, Mao L, et al.: Transthoracic echocardiography in models of cardiac disease in the mouse. Circulation. 1996; 94(5): 1109-1117. PubMed Abstract | Publisher Full Text

7. Yang XP, Liu YH, Rhaleb NE, et al.: Echocardiographic assessment of cardiac function in conscious and anesthetized mice. Am J Physiol. 1999; 277(5 Pt 2): H1967-H1974.

PubMed Abstract

8. Rittirsch D, Huber-Lang MS, Flierl MA, et al:: Immunodesign of experimental sepsis by cecal ligation and puncture. Nat Protoc. 2009; 4(1): 31-36. PubMed Abstract | Publisher Full Text | Free Full Text

9. Hart CY, Burnett JC Jr, Redfield MM: Effects of avertin versus xylazine-ketamine anesthesia on cardiac function in normal mice. Am J Physiol Heart Circ Physiol. 2001; 281(5): H1938-45. PubMed Abstract

10. Matsuda $\mathrm{Y}$, Ohsaka $\mathrm{K}$, Yamamoto $\mathrm{H}$, et al.: Comparison of newly developed inhalation anesthesia system and intraperitoneal anesthesia on the hemodynamic state in mice. Biol Pharm Bull. 2007; 30(9): 1716-1720. PubMed Abstract | Publisher Full Text

11. Collins KA, Korcarz CE, Lang RM: Use of echocardiography for the phenotypic assessment of genetically altered mice. Physiol Genomics. 2003; 13(3): 227-239. PubMed Abstract

12. Butterfield NN, Graf P, Ries $C R$, et al.: The effect of repeated isoflurane anesthesia on spatial and psychomotor performance in young and aged mice. Anesth Analg. 2004; 98(5): 1305-1311, table of contents.

PubMed Abstract | Publisher Full Text

13. Szczesny G, Veihelmann A, Massberg S, et al.: Long-term anaesthesia using inhalatory isoflurane in different strains of mice-the haemodynamic effects. Lab Anim. 2004; 38(1): 64-69.

PubMed Abstract | Publisher Full Text

14. Roth DM, Swaney JS, Dalton ND, et al: Impact of anesthesia on cardiac function during echocardiography in mice. Am J Physiol Heart Circ Physiol. 2002; 282(6): H2134-2140. PubMed Abstract

15. Zanotti-Cavazzoni SL, Guglielmi M, Parrillo JE, et al:: Fluid resuscitation influences cardiovascular performance and mortality in a murine model of sepsis. Intensive Care Med. 2009; 35(4): 748-754. PubMed Abstract | Publisher Full Text

16. Okajima $\mathrm{K}$, Abe $\mathrm{Y}$, Fujimoto $\mathrm{K}$, et al.: Comparative study of high-resolution microimaging with $30-\mathrm{MHz}$ scanner for evaluating cardiac function in mice. $J$ Am Soc Echocardiogr. 2007; 20(10): 1203-1210.

PubMed Abstract | Publisher Full Text

17. Zhang Y, Takagawa J, Sievers RE, et al:: Validation of the wall motion score and myocardial performance indexes as novel techniques to assess cardiac function in mice after myocardial infarction. Am J Physiol Heart Circ Physiol. 2007; 292(2): H1187-1192. PubMed Abstract | Publisher Full Text

18. Lachin JM: The role of measurement reliability in clinical trials. Clin Trials. 2004; 1(6): 553-566.

PubMed Abstract | Publisher Full Text

19. Janssen BJ, De Celle T, Debets JJ, et al.: Effects of anesthetics on systemic hemodynamics in mice. Am J Physiol Heart Circ Physiol. 2004; 287(4): H1618-H1624.

PubMed Abstract | Publisher Full Text

20. Rottman JN, Ni G, Khoo M, et al:: Temporal changes in ventricular function assessed echocardiographically in conscious and anesthetized mice. J Am Soc Echocardiogr. 2003; 16(11): 1150-1157. PubMed Abstract | Publisher Full Text

21. Desai $\mathrm{KH}$, Sato $\mathrm{R}$, Schauble $\mathrm{E}$, et al:: Cardiovascular indexes in the mouse at rest and with exercise: new tools to study models of cardiac disease. Am J Physiol. 1997; 272(2 Pt 2): H1053-1061. PubMed Abstract

22. Janssen BJ, Smits JF: Autonomic control of blood pressure in mice: basic 
physiology and effects of genetic modification. Am J Physiol Regul Integr Comp Physiol. 2002; 282(6): R1545-R1564.

PubMed Abstract

23. Butz GM, Davisson RL: Long-term telemetric measurement of cardiovascular parameters in awake mice: a physiological genomics tool. Physiol Genomics. 2001; 5(2): 89-97.

PubMed Abstract

24. Uechi M, Asai K, Osaka M, et al:: Depressed heart rate variability and arterial baroreflex in conscious transgenic mice with overexpression of cardiac Gsalpha. Circ Res. 1998; 82(4): 416-423. PubMed Abstract | Publisher Full Text

25. Ishizaka S, Sievers RE, Zhu BQ, et al:: New technique for measurement of left ventricular pressure in conscious mice. Am J Physiol Heart Circ Physiol. 2004; 286(3): $\mathrm{H} 1208-1215$

PubMed Abstract | Publisher Full Text

26. Kramer K, van Acker SA, Voss HP, et al:: Use of telemetry to record

electrocardiogram and heart rate in freely moving mice. $J$ Pharmacol Toxicol
Methods. 1993; 30(4): 209-215.

PubMed Abstract | Publisher Full Text

27. Takuma S, Suehiro $\mathrm{K}$, Cardinale $\mathrm{C}$, et al: Anesthetic inhibition in ischemic and nonischemic murine heart: comparison with conscious echocardiographic approach. Am J Physiol Heart Circ Physiol. 2001; 280(5): H2364-H2370. PubMed Abstract

28. Kass DA, Hare JM, Georgakopoulos D: Murine cardiac function: a cautionary tail. Circ Res. 1998; 82(4): 519-522.

PubMed Abstract | Publisher Full Text

29. Wu J, Bu L, Gong H, et al.: Effects of heart rate and anesthetic timing on highresolution echocardiographic assessment under isoflurane anesthesia in mice. J Ultrasound Med. 2010; 29(12): 1771-1778.

PubMed Abstract

30. Picard FA, Depret FL, Zanotti Cavazzoni SL, et al.: Inter and intra-observer reproducibility data for effect of anesthesia on murine cardiac function. Figshare. 2014.

Data Source 


\section{Open Peer Review}

\section{Current Peer Review Status:}

\section{Version 1}

Reviewer Report 15 December 2014

https://doi.org/10.5256/f1000research.4149.r6842

(C) 2014 Riess M. This is an open access peer review report distributed under the terms of the Creative Commons Attribution License, which permits unrestricted use, distribution, and reproduction in any medium, provided the original work is properly cited.

\section{Matthias Riess}

Department of Anesthesiology, Vanderbilt University Medical Center, Nashville, TN, USA

In "Effect of anesthesia level on murine cardiac function" F Picard et al. anesthetized 12 mice three times at different concentrations of the volatile anesthetic isoflurane to test the hypothesis that isoflurane has a dose-dependent negative inotrope and chronotrope effect on myocardial function. Overall, this is an interesting and useful study to help guide basic science investigators when conducting echocardiography in cardiovascular studies in mice. Several questions/concerns, however, would need to be addressed to improve the validity of the data and the value for F1000Research's readers:

1. Please integrate more details on the (revised) statistical analysis into the abstracts as well.

2. Introduction, $2^{\text {nd }}$ paragraph: most importantly, echocardiograpy is non-invasive.

3. Introduction, $2^{\text {nd }}$ paragraph: I do not agree with the statement that "... physiological mechanisms in mice are closely related to those in humans." With a heart rate in the $500 \mathrm{~s}$ and a correspondingly lower stroke volume this is hardly the case. In addition, the body mass to surface ratio and therefore metabolism are different. Please revise accordingly.

4. Introduction, $3^{\text {rd }}$ paragraph: “In fact, heart rate can be used as a proxy for depth of anesthesia." While this may be true for the murine model at hand, depth of anesthesia in general cannot be assessed by heart rate only and strongly depends on the anesthetic used (volatile vs intravenous, cardiovascular side effects vary greatly among drugs, hemodynamic status, acutely and chronically administered concurrent medications, etc). Please revise.

5. Material and Methods, $1^{\text {st }}$ paragraph: please use the current version of the Guide.

6. Material and Methods, $2^{\text {nd }}$ paragraph (Experimental Protocols), and study design in general: the authors seem to exchange dependent and independent variables in their experiments. Either isoflurane is given at a predetermined end tidal concentration as an independent 
variable with a negligible standard deviation in its concentration in each group, then heart rate is a truly dependent variable. If, however, isoflurane is titrated to achieve a certain heart rate, the latter turns into an independent variable while isoflurane becomes the dependent variable. Either way, isoflurane concentrations and heart rates in each group need to be shown as mean plus/minus standard deviation in case of normal distribution or median and quartiles if not normally distributed. Please revise, including table 1.

7. Material and Methods, $4^{\text {th }}$ paragraph: what were the animals' temperatures? Deviations in temperature may have a significant effect on heart rate independent of the isoflurane concentration.

8. Material and Methods, $4^{\text {th }}$ paragraph: was an end tidal isoflurane concentration measured or are the concentrations provided from the vaporizer setting? If so, what fresh gas flow was used?

9. Statistical analysis: more than one comparison requires an ANOVA with post-hoc comparisons, not repeated t-tests to avoid a type I error. For non-parametric testing see below.

10. Table 1: The statistical symbols are largely redundant, e.g. if deep is different to light, light does not have to be shown again to be different to deep etc. Please simplify.

11. Figure 1: The nature of the box plots suggests that most of the data are not normally distributed. Therefore, non-parametric tests and data presentation are necessary. Please revise.

12. As laid out before, due to a switch between strictly independent and dependent variables there appears to be a greater than necessary heterogeneity in the isoflurane concentrations in any of the three groups. Therefore, please plot the outcome data presented in panels A through $D$ of figure 1 as scatter plots with the isoflurane concentrations on the $x$-axis and the chosen outcome on the $y$-axis and conduct regression and correlation analyses to emphasize the take home points of this study.

Competing Interests: No competing interests were disclosed.

\section{I confirm that I have read this submission and believe that I have an appropriate level of expertise to confirm that it is of an acceptable scientific standard, however I have significant reservations, as outlined above.}

Reviewer Report 07 October 2014

https://doi.org/10.5256/f1000research.4149.r6357

(c) 2014 Fayssoil A. This is an open access peer review report distributed under the terms of the Creative Commons Attribution License, which permits unrestricted use, distribution, and reproduction in any medium, provided the original work is properly cited. 


\section{Abdallah Fayssoil}

Critical Care Unit, Raymond Poincare Hospital, Garches, France

This is interesting and original research that evaluates the effect of anesthesia level on murine cardiac function, using a non-invasive approach. The data are interesting and will be helpful to the scientific community.

Competing Interests: No competing interests were disclosed.

I confirm that I have read this submission and believe that I have an appropriate level of expertise to confirm that it is of an acceptable scientific standard.

The benefits of publishing with F1000Research:

- Your article is published within days, with no editorial bias

- You can publish traditional articles, null/negative results, case reports, data notes and more

- The peer review process is transparent and collaborative

- Your article is indexed in PubMed after passing peer review

- Dedicated customer support at every stage

For pre-submission enquiries, contact research@f1000.com

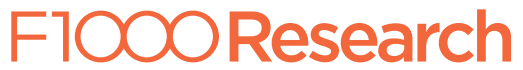

